\title{
Controlled assembly of fibronectin nanofibrils triggered by random copolymer chemistry
}

Hayk Mnatsakanyan ${ }^{1}$, Patricia Rico ${ }^{1,2}$, Eleni Grigoriu ${ }^{3}$, Aarón Maturana Candelas ${ }^{1}$, Aleixandre Rodrigo-Navarro ${ }^{3}$, Manuel Salmeron-Sanchez ${ }^{3 *}$, Roser Sabater i Serra ${ }^{1^{*}}$

${ }^{1}$ Center for Biomaterials and Tissue Engineering. Universitat Politècnica de València, 46022 València, Spain

${ }^{2}$ CIBER en Bioingeniería, Biomateriales y Nanomedicina, Valencia, Spain

${ }^{3}$ Division of Biomedical Engineering, School of Engineering, University of Glasgow, United Kingdom

\section{Corresponding authors:}

Roser Sabater i Serra (rsabater@die.upv.es)

Manuel Salmeron-Sanchez (Manuel.Salmeron-Sanchez@glasgow.ac.uk)

\begin{abstract}
Fibronectin fibrillogenesis is the physiological process by which cells elaborate a fibrous FN matrix. Poly(ethyl acrylate), PEA, has been described to induce a similar process upon simple adsorption of fibronectin (FN) from a protein solution - in the absence of cells -leading to the so-called material-driven fibronectin fibrillogenesis. Poly(methyl acrylate), PMA, is a polymer with very similar chemistry to PEA, on which FN is adsorbed keeping the globular conformation of the protein in solution. We have used radical polymerisation to synthesise copolymers with controlled EA/MA ratio seeking to modulate the degree of FN fibrillogenesis. The physico-chemical properties of the system were studied using dynamicmechanical analysis, differential scanning calorimetry and water contact angle. Both the degree of FN fibrillogenesis and the availability of the integrin binding region of FN directly depend on the percentage of EA in the copolymer, whereas the same total amount of FN was adsorbed regardless the EA/MA ratio. Cell morphology adhesion and differentiation of murine $\mathrm{C} 2 \mathrm{C} 12$ were shown to depend on the degree of FN fibrillogenesis previously attained on the material surface. Myogenic differentiation was enhanced on the copolymers with higher EA content, i.e. more interconnected FN fibrils.
\end{abstract}

Keywords: Fibronectin, Fibrillogenesis, Biointerface, Bioactive substrates, Cell adhesion, Cell differentiation. 


\section{Introduction}

The chemical and physical properties of biomaterials determine the cell/material interaction. ${ }^{1-}$ ${ }^{3}$ The first biological event which occurs on the material surface when biomaterials are either studied in vitro or implanted in vivo is protein adsorption from culture media or physiological fluids respectively. ${ }^{4-6}$ Differences in protein absorption and configuration on the substrate play a pivotal role in cellular behaviour; including cell adhesion, proliferation, migration and differentiation. $^{7-9}$

Integrins are the major receptors for proteins adsorbed on material surface and trigger cell adhesion and activate diverse intracellular signalling pathways to regulate cell fate..$^{10,11}$ Integrins are also involved in assembling fibrillar matrix networks from soluble secreted matrix proteins, e.g. the formation of fibrillar fibronectin matrices. ${ }^{12}$

Fibronectin $(\mathrm{FN})$ is organised into a fibrillar network through direct interactions with cell surface receptors. ${ }^{13}$ FN fibrillogenesis is a cell-mediated matrix assembly process during which FN undergoes conformational changes that expose fibronectin-binding sites and promote intermolecular interactions needed for fibril formation. ${ }^{14} \mathrm{FN}$ fibrillar matrices have diverse functional properties: provide binding sites for other ECM proteins, act as a structural support for cells and transduce cell signalling. ${ }^{13,15}$

Several studies have demonstrated that surface chemistry is a key parameter that determines the amount and conformation of adsorbed FN. ${ }^{16-18}$ In previous works, we have shown the ability of certain material surfaces (in particular poly(ethyl acrylate) - PEA) to promote the organization of fibronectin in to physiological-like (nano)networks, a process that we named material-driven fibronectin fibrillogenesis. ${ }^{19-22}$ There, the adsorption of individual FN molecules on the material surface allows the exposure of FN self-assembly sites to drive FNFN interaction and the organisation of (nano)networks at the material interface, in absence of 
cells. After FN adsorption on PEA, a biologically active FN (nano)network is spontaneously assembled on the material surface. This phenomenon does not occur on poly(methyl acrylate) (PMA), which differs from PEA in one single carbon in the side chain, where FN is adsorbed keeping the globular conformation. ${ }^{20,21}$ Other ways to induce the formation of fibronectin fibrils on material surface, mostly triggered by force, have been reported elsewhere. ${ }^{20,23-25}$

Here, a series of copolymers with controlled ethyl acrylate/methyl acrylate (EA/MA) ratio were synthetised seeking to modulate the degree of FN fibrillogenesis. We investigated FN adsorption and conformation as a function of the amount of EA in the copolymers. Afterwards, we assessed the effect of the degree of fibrillogenesis on cell adhesion and cell differentiation using C2C12 myoblasts.

The main novelty of this work is that we have now a way to control the degree of this process of organisation of fibronectin into nanonetworks by using the percentage of ethyl acrylate in a random copolymer that consitsts of EA (which polymer induces fibrillogenesis), and MA (which polymer adsorbs FN in a globular shape). Overall, this paper shows that the composition of the copolymer, i.e. the EA fraction, determine the degree of fibrillogenesis and in turn this controls cell fate, including cell differentiation.

\section{Materials and methods}

\subsection{Materials}

Copolymers sheets (ca. $0.4 \mathrm{~mm}$ of thickness) were obtained by radical polymerisation of a solution of ethyl acrylate (EA), methyl acrylate, MA, (Sigma-Aldrich, Steinheim, Germany) and merging ratios of EA/MA of 70/30, 50/50 and 30/70 wt.\% using $1 \%$ wt benzoin (98\% pure, Scharlau) as photoinitiator. The reaction was carried out in ultraviolet light for $24 \mathrm{~h}$. After polymerisation, low molecular weight substances were extracted from the material by drying in vacuum to constant weight. Besides, pure poly(ethyl acrylate), PEA, and 
poly(methyl acrylate), PMA, sheets were prepared in the same way. Thereafter, materials with the afore-mentioned composition will be named as PEA100, PEA70, PEA50, PEA30 and PMA100.

Thin films were prepared using a spin-coater (Brewer Science). Each one of the synthesised polymers and copolymers was dissolved in toluene at concentration between 4 and $6 \mathrm{wt} \%$. Spin casting was performed on 12 and $25 \mathrm{~mm}$ glass coverslips at $3000 \mathrm{rpm}$ for $30 \mathrm{~s}$. Samples were dried in vacuum at $60{ }^{\circ} \mathrm{C}$ before further characterization. The obtained films are not porous and have approximately $500 \mathrm{~nm}$ of thickness.

\subsection{Physico-chemical characterization of materials}

\subsubsection{Differential scanning calorimetry}

Differential scanning calorimetry (DSC) measurements were performed in a Mettler Toledo 823e apparatus on samples between 5 and $10 \mathrm{mg}$. Nitrogen gas was purged through the DSC cell with a flow rate of $20 \mathrm{ml} / \mathrm{min}$. After erasing the effects of any previous thermal history by heating to $100{ }^{\circ} \mathrm{C}$, the samples were subjected to a cooling scan down to $-60{ }^{\circ} \mathrm{C}$ at $10{ }^{\circ} \mathrm{C} / \mathrm{min}$, followed by a heating scan from that temperature up to $100{ }^{\circ} \mathrm{C}$ at a rate of $10{ }^{\circ} \mathrm{C} / \mathrm{min}$. The glass transition temperature $\left(T_{g}\right)$ was calculated from the cooling scan as the inflexion point of the specific heat capacity $\left(c_{p}\right)$ versus temperature; which coincides with the minimum in the temperature derivative of $c_{p}$.

\subsubsection{Dynamic-mechanical analysis (DMA)}

Dynamic-mechanical analysis was performed using a Seiko DMS210 apparatus at a frequency of $1 \mathrm{~Hz}$ in the tension mode. The temperature dependence of the storage modulus $\left(E^{\prime}\right)$, loss modulus $\left(E^{\prime \prime}\right)$, and loss tangent $(\tan \delta)$ was measured in the temperature range -70 to $70{ }^{\circ} \mathrm{C}$ at a heating rate of $2{ }^{\circ} \mathrm{C} / \mathrm{min}$. The samples for these measurements were prismatic (ca. $15 \times 8 \times 1 \mathrm{~mm})$. 


\subsubsection{Water contact angle on the different substrates}

The surface wettability was investigated by water contact angle (WCA) measurements. To measure the static contact angles, a $3 \mu 1$ drop was deposited onto the surface and stabilisation allowed $(\sim 10 \mathrm{~s})$. When the three-phase boundary is in motion, the angles formed are called dynamic contacts angles and they are further subdivided into advancing and receding contact angles. The advancing contact angles was measured as drop expanded, whereas the receding contact angle whole the liquid was removed from the drop. The difference between the advancing and the receding contact angle is called hysteresis $(\mathrm{H})$. Measurements were carried out using a Theta optical tensiometer (Biolin Scientific). All measurements were performed six times for each substrate.

\subsection{Atomic Force Microscope (AFM) experiments}

Atomic force microscopy (AFM) was performed in a Multimode AFM equipped with NanoScope IIIa controller from Veeco (Manchester, UK) operating in tapping mode in air. Nanoscope 5.30r2 software version was used for image processing and analysis. Sicantilevers from Veeco (Manchester, UK) were used with force constant of $2.8 \mathrm{~N} / \mathrm{m}$ and resonance frequency of $75 \mathrm{kHz}$. The phase signal was set to zero at a frequency $5-10 \%$ lower than the resonance one. Drive amplitude was $600 \mathrm{mV}$ and the amplitude setpoint Asp was 1.8

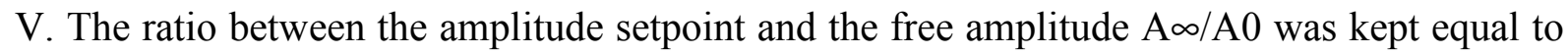
0.8 .

In order to study the topography of the surfaces, roughness of spin-coated samples was measured from AFM images (size $1 \mu \mathrm{m} \times 1 \mu \mathrm{m}$ ). $\mathrm{R}_{\mathrm{q}}$ (root mean square average of height deviations taken from the mean image data plane) was calculated using the roughness subroutine in the Nanoscope software. 
To analyze FN organisation on material surfaces, samples prepared by spin-coating were covered with a solution of concentration 5 or $20 \mu \mathrm{g} / \mathrm{ml}$ for $10 \mathrm{~min}$ (FN from human plasma (Sigma-Aldrich) and PBS). After adsorption, the samples were rinsed in PBS to eliminate the non-adsorbed protein.

Image processing and fractal dimension $\left(F_{D}\right)$ calculation via the box-counting method $(\mathrm{BCM})^{26}$ were performed by using FracLac and ImageJ software. ${ }^{27,28}$

\subsection{FN adsorption}

FN from human plasma was adsorbed from a solution of concentration $20 \mu \mathrm{g} / \mathrm{ml}$ in DPBS for $1 \mathrm{~h}$ (for complete saturation) on $12 \mathrm{~mm}$ samples. After adsorption, supernatant was collected and quantified by Micro BCA Protein Assay Kit (Thermo Scientific). The adsorbed FN was obtained as the difference between the amount of FN in the initial solution and in the supernatant.

\subsection{FN conformation}

The relationship between the degree of FN fibrillogenesis and the availability of FN domains on the material surface was investigated by means of an enzyme-linked immunosorbent assay (ELISA). FN was adsorbed from a solution with a concentration of $20 \mu \mathrm{g} / \mathrm{ml}$ in DPBS for $1 \mathrm{~h}$ on spin coated substrates $(12 \mathrm{~mm})$. Then, samples were rinsed with DPBS to eliminate the non-adsorbed protein. After adsorption, samples were blocked in $1 \%$ BSA/DPBS and incubated with primary antibody Anti-Fibronectin cell binding domain (1:500 MAB1937, Merck-Millipore) in blocking solution for $1 \mathrm{~h}$ at $37{ }^{\circ} \mathrm{C}$. Samples were then rinsed in $0.5 \%$ Tween-20/DPBS and incubated with alkaline phosphatase conjugated secondary antibody (1:5000) for $1 \mathrm{~h}$ at $37^{\circ} \mathrm{C}$ followed by incubation with 4-methylumbelliferyl phosphate substrate (Sigma-Aldrich) for $45 \mathrm{~min}$ at $37{ }^{\circ} \mathrm{C}$. Reaction products were quantified using a fluorescence plate reader (Victor III, PerkinElmer) at $365 \mathrm{~nm} / 465 \mathrm{~nm}$. 


\subsection{Cell culture}

Murine C2C12 myoblasts (Sigma-Aldrich) were maintained in Dubelcco's Modified Eagle Medium (DMEM) supplemented with $20 \%$ foetal bovine serum and $1 \%$ penicillinstreptomycin in a humidified atmosphere at $37 \mathrm{C}$ and $5 \% \mathrm{CO}_{2}$. Cells were subcultured before reaching confluence (approximately every 2 days).

For cell adhesion, myoblasts were seeded at low density $\left(5000\right.$ cells $\left./ \mathrm{cm}^{2}\right)$ onto different materials after coating with $20 \mu \mathrm{g} / \mathrm{ml}$ of FN in DMEM supplemented with $1 \%$ penicillinstreptomycin and in absence of serum in medium.

In myoblast differentiation experiments, $\mathrm{C} 2 \mathrm{C} 12$ cells were seeded at confluence density (20000 cells $/ \mathrm{cm}^{2}$ ) onto the materials coated with $20 \mu \mathrm{g} / \mathrm{ml}$ of FN in DMEM supplemented with differentiation medium in absence of serum (1\% insulin-transferrin-selenium and $1 \%$ penicillin-streptomycin). For the experiments including contractility inhibitors, blebbistatin was added to the culture medium at $10 \mathrm{mM}$ after $2 \mathrm{~h}$ of culture and maintained for 4 days.

\subsection{Cell adhesion experiments}

After $3 \mathrm{~h}$ of culture, C2C12 cells were washed in DPBS (Gibco) and fixed in 10\% formalin solution (Sigma) at $4{ }^{\circ} \mathrm{C}$. Cells were incubated with permeabilizing buffer (103 g/L sucrose, $2.92 \mathrm{~g} / \mathrm{L} \mathrm{NaCl}, 0.6 \mathrm{~g} / \mathrm{L} \mathrm{MgCl}_{2}, 4.76 \mathrm{~g} / \mathrm{L}$ HEPES buffer, $5 \mathrm{ml} / \mathrm{L}$ Triton X-100, $\mathrm{pH}$ 7.2) for 5 min, next blocked in 1\% BSA/DPBS and incubated with primary antibody against vinculin (Sigma, 1:400). Samples were then rinsed in DPBS/ 0.5\% Tween-20. Cy3-conjugated antimouse secondary antibody in 1\% BSA/DPBS (Invitrogen) and BODIPY FL phallacidin (Invitrogen) were used. Finally, samples were washed and mounted in Vectashield with DAPI (Vector Laboratories). Eclipse 80i (Nikon) fluorescent microscope was used for cellular imaging. After imaging, cell morphology was analysed by ImageJ software. 


\subsection{Focal adhesion kinase activity}

After $3 \mathrm{~h}$ of $\mathrm{C} 2 \mathrm{C} 12$ cells culture on samples, total protein extraction was performed by lysing the cells with RIPA buffer $(50 \mathrm{mM}$ Tris- $\mathrm{HCl} \mathrm{pH} 7.4,1 \%$ nonidet $\mathrm{p}-40,0.25 \%$ Nadeoxycholate, $150 \mathrm{mM} \mathrm{NaCl}$ and $1 \mathrm{mM}$ EDTA) supplemented with protease inhibitor cocktail tablets (Roche). The lysates were concentrated with Microcon YM-30 Centrifugal Filters units (Millipore) and separated in 8\%-SDS PAGE under denaturing conditions as described

elsewhere. ${ }^{29}$ Proteins were transferred to a PVDF membrane (GE Healthcare) using a semidry transfer cell system (Biorad), and blocked by immersion in 5\% skimmed milk in PBS. To analyse the expression patterns of FAK and phosphorylated FAK on tyrosine 397 (pFAK), the blots were incubated separately with primary antibody against FAK (Millipore, 1:2500), pFAKs (Millipore, 1:250) and $\alpha$-Tubuline (Abcam, 1:20000) as a loading control in PBS/0.1\% Tween-20/2\% skimmed milk for $1 \mathrm{~h}$ at room temperature and washed with PBS/0.1\% Tween-20. The blots were subsequently incubated in HRP-conjugated secondary antibody (GE Healthcare) diluted 1:20000 in PBS/0.1\% Tween-20/2\% skimmed milk. The Supersignal West Femto Maximum Sensitivity Substrate (Pierce) was used prior to exposing the blots to X-ray film. Image analysis of the western bands was conducted using ImageJ software.

\subsection{Myogenic differentiation experiments}

C2C12 cells were cultured on FN-coated materials for 4 days under differentiation conditions and immunostained for sarcomeric $\alpha$-actinin. Cells were fixed in $70 \%$ ethanol $/ 37 \%$ formaldehyde/glacial acetic acid (20:2:1) for 10 minutes and then blocked in 5\% goat serum in DPBS for $1 \mathrm{~h}$. Samples were sequentially incubated with primary antibody anti-arcomeric $\alpha$-actinin (Abcam, 1:200) and secondary antibody anti-mouse AlexaFluor-488 (Invitrogen, 1:200) for $1 \mathrm{~h}$, and then washed with DPBS/0.5 \% Tween 20. Finally the samples were mounted with Vectashield containing DAPI. Eclipse 80i (Nikon) fluorescent microscope was 
used for cellular imaging. Myogenic differentiation was calculated as the percentage of cells positive for sarcomeric $\alpha$-actinin using ImageJ software.

\subsection{Statistics}

All experiments were performed at least three times unless otherwise noted. Data were reported as mean - standard error. To establish if our data follow a normal distribution, D'Agostino-Pearson omnibus test was resorted.

Results were analysed by one-way ANOVA using GraphPad Prism 6.0. If treatment level differences were determined to be significant, pair-wise comparisons would perform using a Tukey in case of normal distribution of data or a Dunn's test in the contrary case. A 95\% confidence level was considered significant.

\section{Results}

\subsection{Polymers and copolymers physico-chemical properties}

Fig. 1a shows the cooling DSC thermograms for the pure homopolymers and copolymers. Only one glass transition was found in the EA/MA copolymers, located between those of the corresponding homopolymers. As the amount of MA increases, the glass transition temperature $\left(T_{g}\right)$ increases according to the copolymer composition (Table 1$)$. The dynamicalmechanical spectra, elastic modulus $\left(E^{\prime}\right)$ and loss tangent $(\tan \delta)$ is depicted in Fig. 1c and 1d. Pure polymers show a single maximum in $\tan \delta$ and a drop in $E$, which corresponds to the main relaxation, related to the glass transition. Likewise, copolymers present one single relaxation process, placed between those of the corresponding homopolymers. The magnitude and temperature of the maximum of $\tan \delta$ depend on composition: the higher the amount of EA units the lower the intensity and temperature of this main relaxation. The elastic modulus measured at $37^{\circ} \mathrm{C}$ for the copolymers, presents values in between both homopolymers (Table 1), increasing monotonically as the amount of MA in the system does. Static and dynamic 
water contact angle measurements (Fig. 2a) are quite similar throughout the copolymers with comparable hysteresis, which confirms no differences in wettability regardless of the EA/MA ratio.

Surface topograpy, caracterized by the roughness parameter $\mathrm{R}_{\mathrm{q}}$ obtained from AFM images, shows no significant differences between copolymers (Table 1). All the spin-coated surfaces are rather smooth at the nanoscale and homogeneneous for the copolymer series.
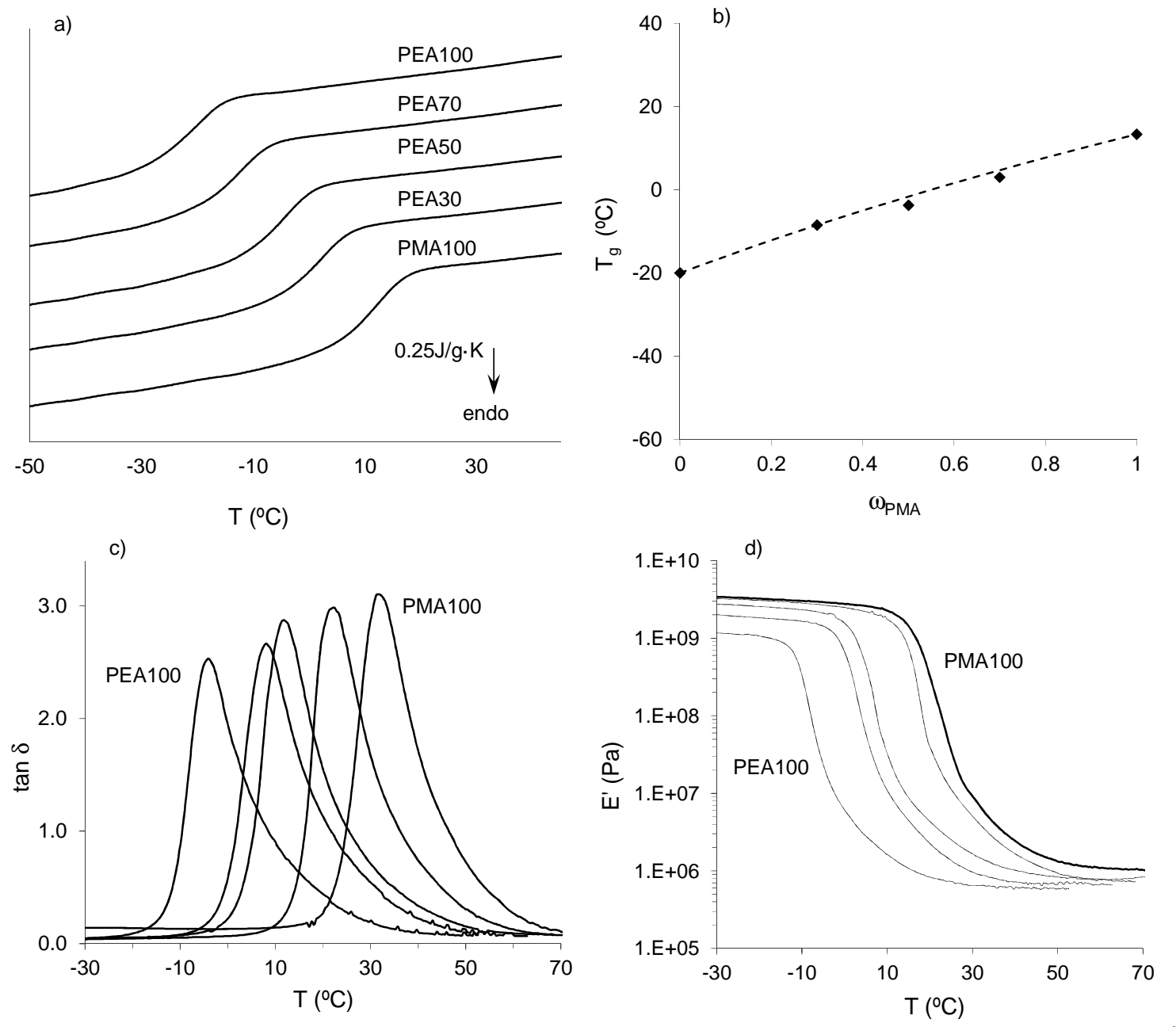

Fig. 1. a) DSC thermograms at a cooling rate of $10{ }^{\circ} \mathrm{C} / \mathrm{min}$. b) Couchman-Karasz prediction and experimental glass transition values $\left(T_{g}\right)$. c) Mechanical loss tangent ( $\tan \delta$ ) and d) elastic modulus $\left(E^{\prime}\right)$ measured at $1 \mathrm{~Hz}$. 
a)

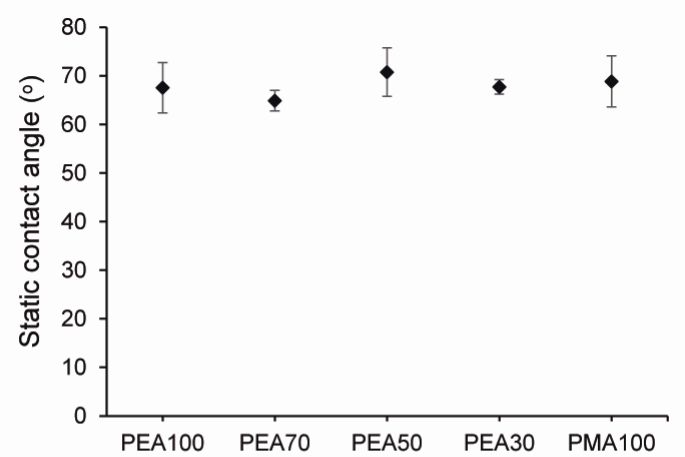

b)

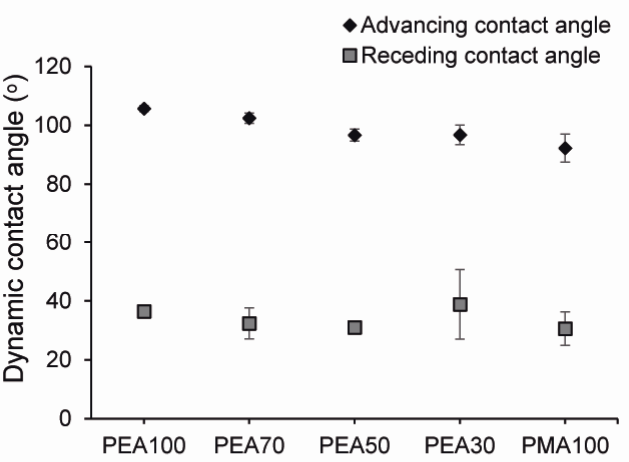

c)

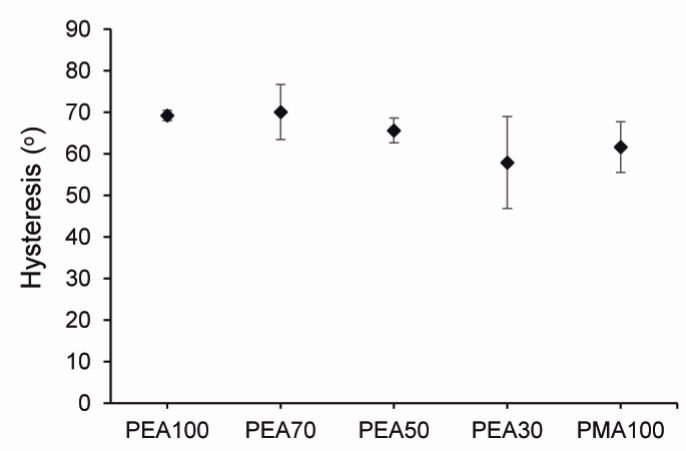

Fig. 2. Water contact angle on the different substrates. a) Static contact angle. b) Dynamic contact angle and c) hysteresis.

Table 1. Glass transition temperature $\left(T_{g}\right)$, elastic modulus $\left(E^{\prime}\right)$ at $37^{\circ} \mathrm{C}$ and roughness parameter $\mathrm{R}_{\mathrm{q}}$.

\begin{tabular}{lccc}
\hline Sample & $\mathbf{T}_{\mathbf{g}}\left({ }^{\mathbf{0}} \mathbf{C}\right)$ & $\mathbf{E}^{\prime}(\mathbf{k P a})$ & $\mathbf{R}_{\mathbf{q}}(\mathbf{n m})$ \\
\hline PEA100 & $-20 \pm 1$ & $620 \pm 5$ & 0.288 \\
PEA70 & $-8 \pm 1$ & $750 \pm 5$ & 0.316 \\
PEA50 & $-4 \pm 1$ & $1100 \pm 10$ & 0.291 \\
PEA30 & $3 \pm 1$ & $2130 \pm 10$ & 0.294 \\
PMA100 & $13 \pm 1$ & $3100 \pm 10$ & 0.265 \\
\hline
\end{tabular}

\subsection{FN organisation on material surfaces}

AFM images (Fig. 3a) show FN distribution on the copolymers after the adsorption of FN from solutions with concentration of 5 and $20 \mu \mathrm{g} / \mathrm{ml}$. Different degrees of fibrillogenesis were 
found in dependence of the EA/MA ratio in the copolymers. As expected, PEA100 shows a complete interconnected (nano)network of FN fibrils from the solution of concentration 20 $\mu \mathrm{g} / \mathrm{ml}$, whereas PMA100 presents a globular FN conformation after adsorption. The density of interconnected fibrils decreases with higher amount of MA units in the copolymers, resulting in a lower degree of fibrillogenesis compared to PEA 100. If FN is adsorbed from a solution of concentration $5 \mu \mathrm{g} / \mathrm{ml}$ (Fig. 3a), this fact becomes even more evident. In particular, the fibrillar organisation is virtually lost on PEA50 and PEA30, whereas the surfaces with higher ratio EA/MA show FN fibrils, but lacking full interconnection between them.

a)

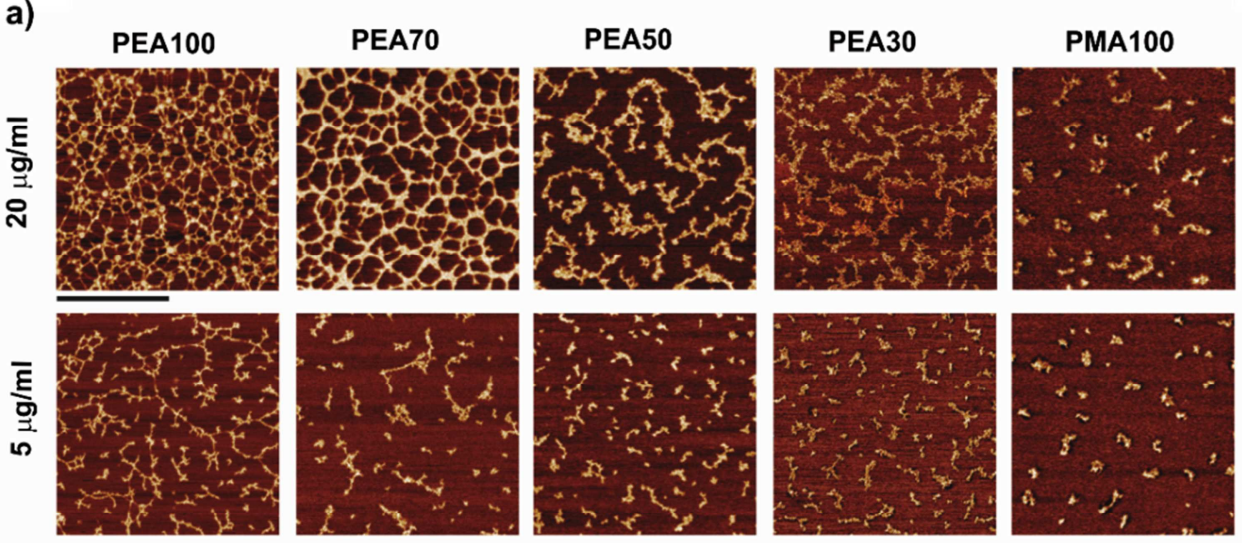

b)

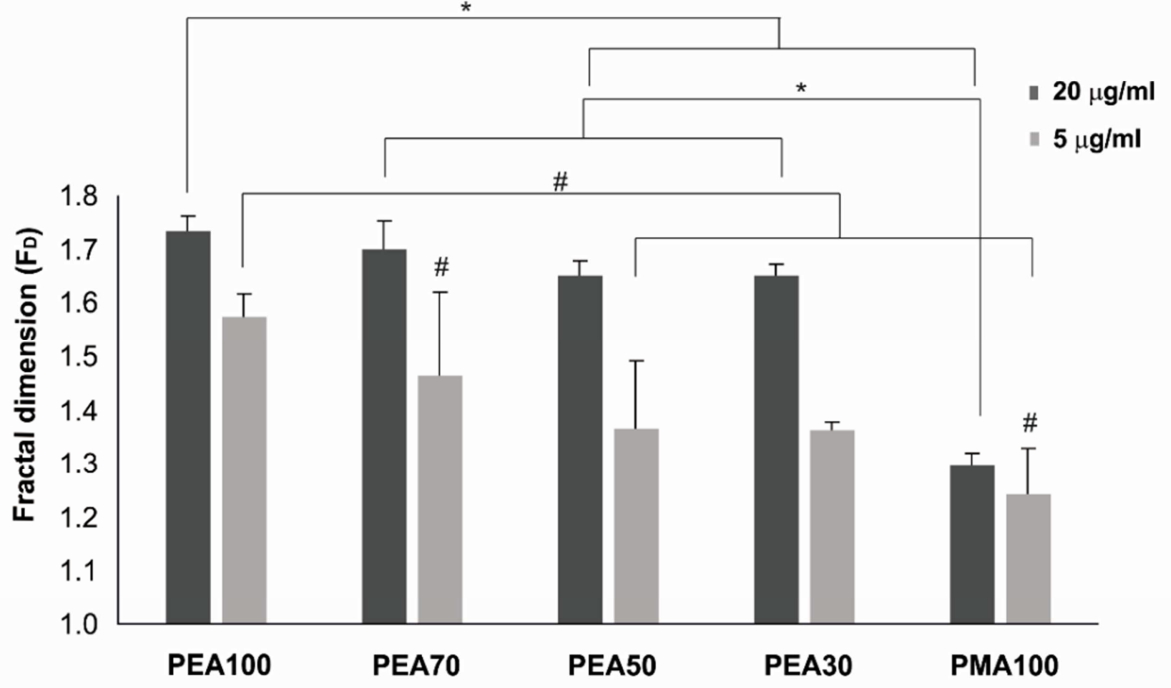

Fig. 3. Material-driven degree of FN fibrillogenesis. a) AFM images (phase magnitude) of FN adsorbed on material substrates for $10 \mathrm{~min}$ from solutions with a concentration of 5 and 20 $\mu \mathrm{g} / \mathrm{ml}$. The scale bar is $0.5 \mu \mathrm{m}$. b) Fractal dimension $\left(F_{D}\right)$ calculated from AFM images. 


\subsubsection{FN conformation on material surfaces}

The quantification of the amount of adsorbed FN on the copolymers show no significant differences throughout the series (Fig. 4a). Nevertheless, ELISA with the monoclonal antibody mAb1937 (against $\mathrm{FNIII}_{8}$ ) suggests different availability of the integrin binding site of $\mathrm{FN}$ in dependence of the EA/MA ratio. $\mathrm{FNIII}_{8}$ is better exposed on PEA100 and it decreases monotonically as the amount of MA in the copolymer increases (Fig. 4b).

a)

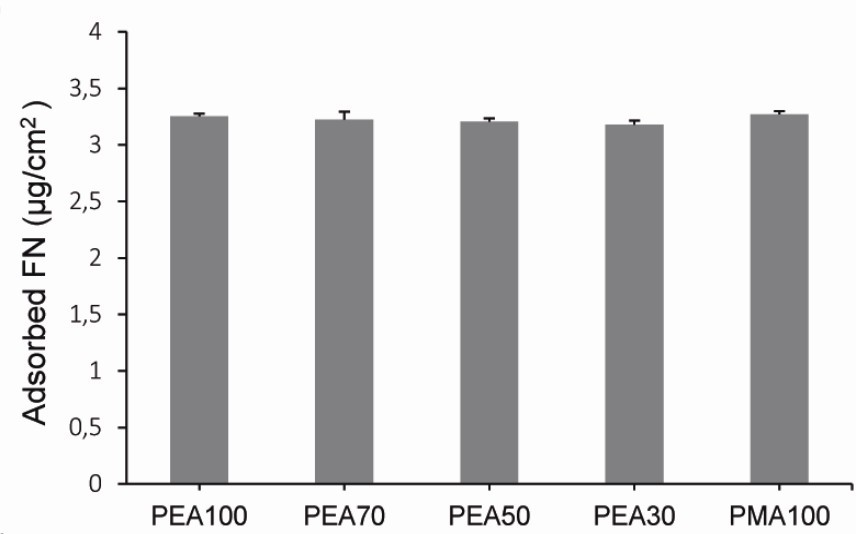

b)

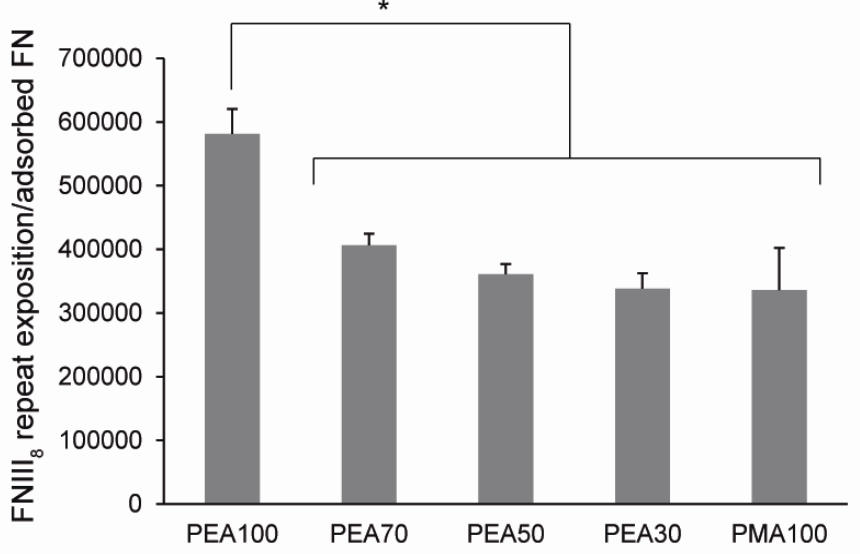

Fig. 4. Fibronectin conformation on material surfaces. a) Surface density of adsorbed FN after $1 \mathrm{~h} . \mathrm{b})$ Exposition of $\mathrm{FNIII}_{8}$ repeat on surfaces obtained by enzyme-linked immunosorbent assay (ELISA).

\subsection{Myoblast adhesion on FN coated substrates}

Cell adhesion was studied on the copolymers coated with FN (with different degree of FN fibrillogenesis) after $3 \mathrm{~h}$ of culture in serum free conditions and under low density seeding to minimise cell-cell contacts $\left(5000\right.$ cells $\left./ \mathrm{cm}^{2}\right)$. Immunofluorescence for the focal adhesion 
protein vinculin was performed. Attached cells with well developed focal adhesions were observed on all substrates regardless the composition of the copolymer, i.e. the degree of FN fibrillogenesis on the material surface. Cells were slightly bigger but with similar shape (circularity) on copolymers with higher content of EA and then higher degree of FN fibrillogenesis (Fig. 5).
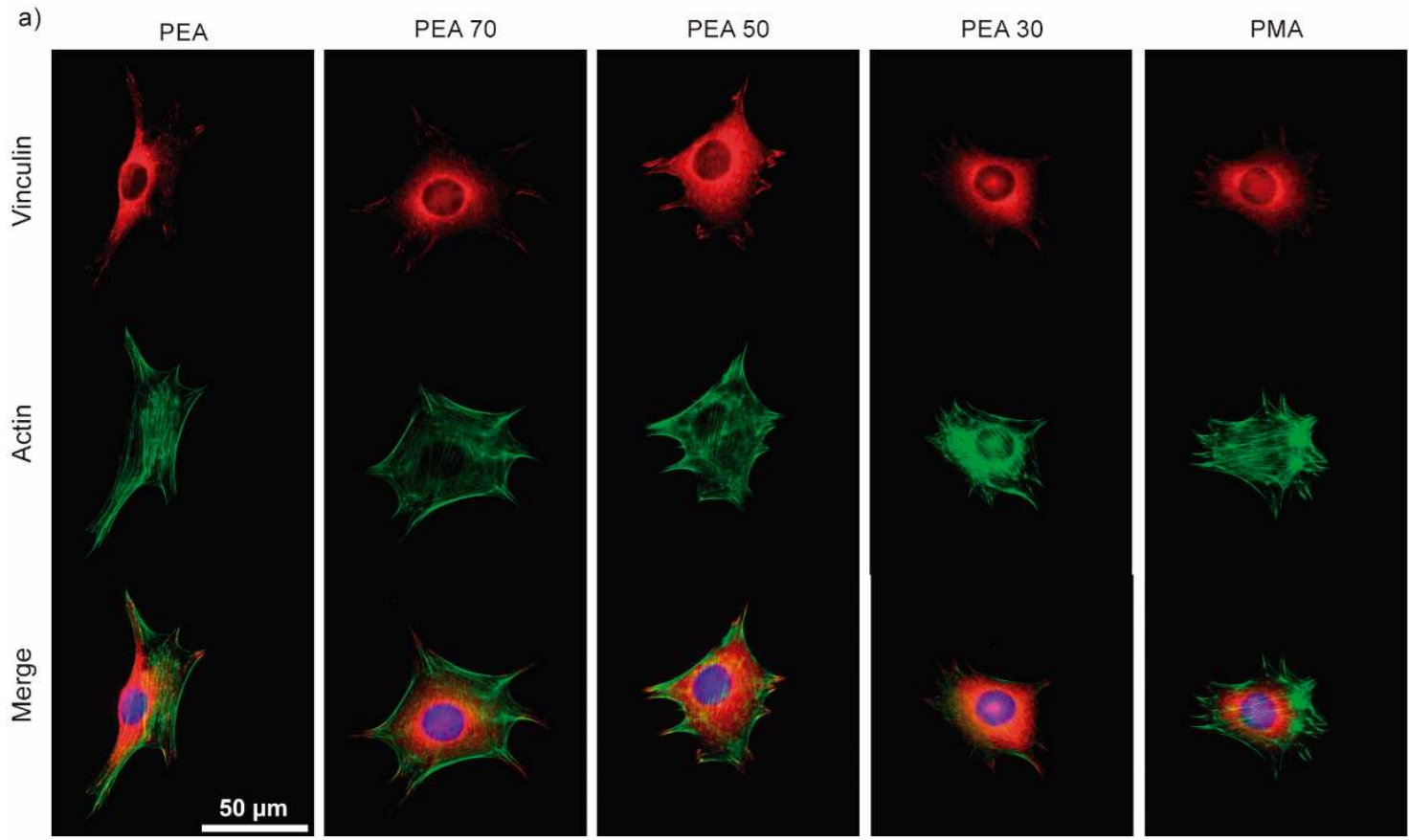

b)

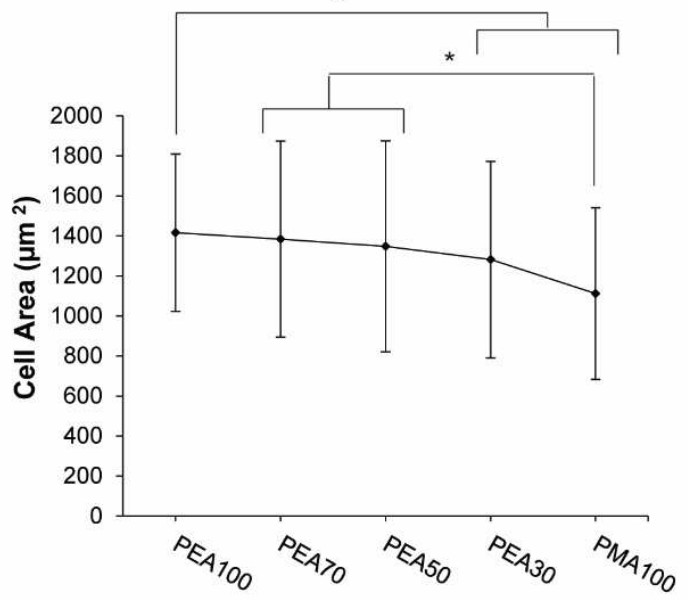

c)

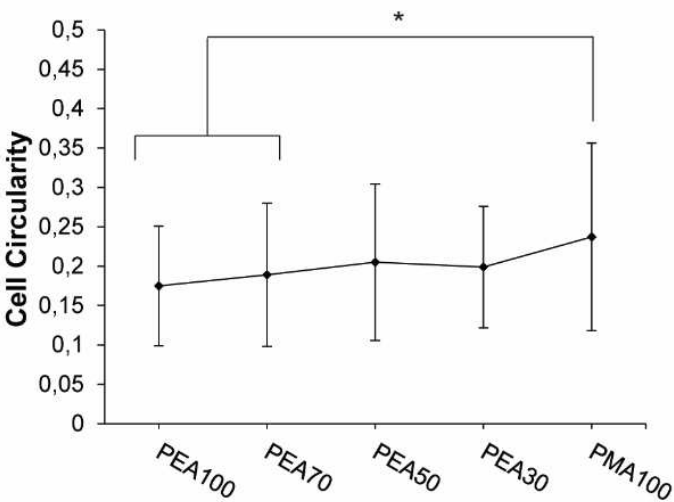

Fig. 5. Adhesion of $\mathrm{C} 2 \mathrm{C} 12$ cells after 3 hours culture on $\mathrm{FN}$ coated materials. a) Immunofluorescence for vinculin. b) Cell area and c) cell circularity. 
We then investigated the starting of signalling cascades on the different copolymers by quantifying the phosphorylation of FAK in tyrosine 397. Results in Fig. 6a shows that the degree of FN fibrillogenesis attained on the different copolymers has no influence on total FAK expression. However, the level of phosphorylation of FAK (pFAK) was higher on copolymers with higher EA content, i.e, on which FN is assembled with higher degree of fibrillogenesis (Fig. 6b).

a)

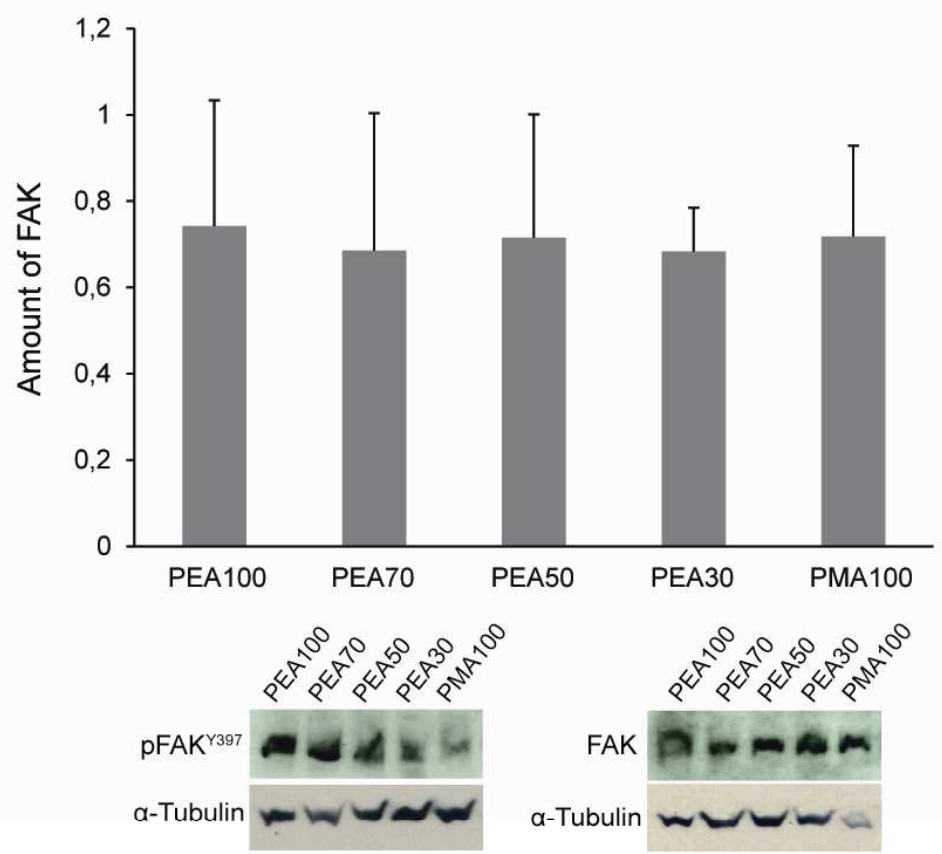

b)

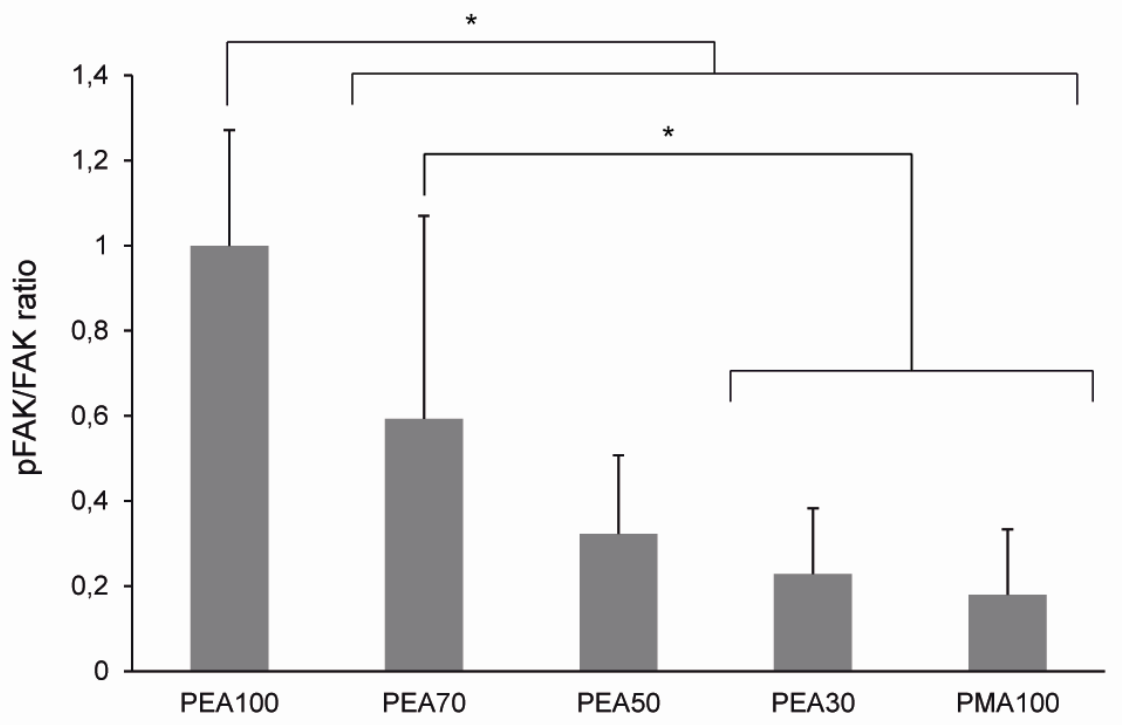

Fig. 6. Expression of focal adhesion kinase (FAK) on $\mathrm{C} 2 \mathrm{C} 12$ cells after $3 \mathrm{~h}$ culture on FN coated materials. a) FAK expression and bands from Western Blot. b) Determination of FAK activity obtained as $\mathrm{pFAK} / \mathrm{FAK}$ ratio. 


\subsection{Myoblast differentiation}

In order to analyse the influence of different degrees of FN fibrillogenesis on myoblast differentiation, cells were cultured for 4 days in ITS containing medium and afterwards stained for sarcomeric $\alpha$-actinin, a protein expressed in differentiated myoblasts. ${ }^{30}$ Myoblast differentiation depends on the degree of fibrillogenesis (Fig. 7). PEA and copolymers with high EA content show high levels of differentiated myoblasts (even higher than collagen, which is the gold standard for myoblast differentiation). However, as the degree of fibrillogenesis decreases (lower EA contents), the fraction of differentiated cells decreases up to PMA100, on which FN is adsorbed in a globular shape and the percentage of differentiated cells is the lowest one. This result shows direct relationship between myoblast differentiation and the distribution of FN into (nano)networks at the material interface.

a)

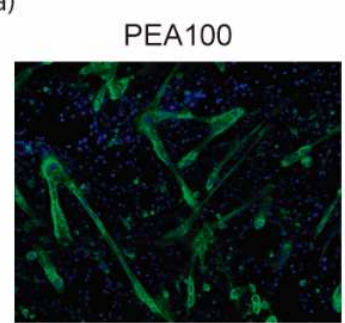

PEA50

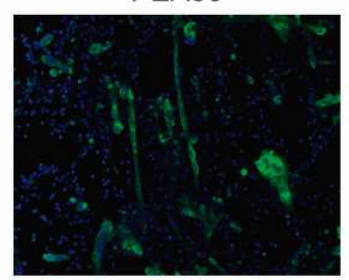

PMA100

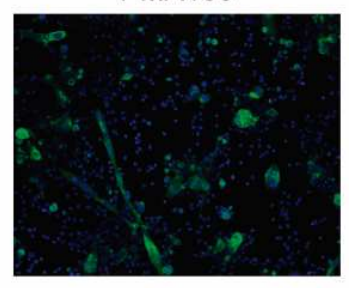

b)
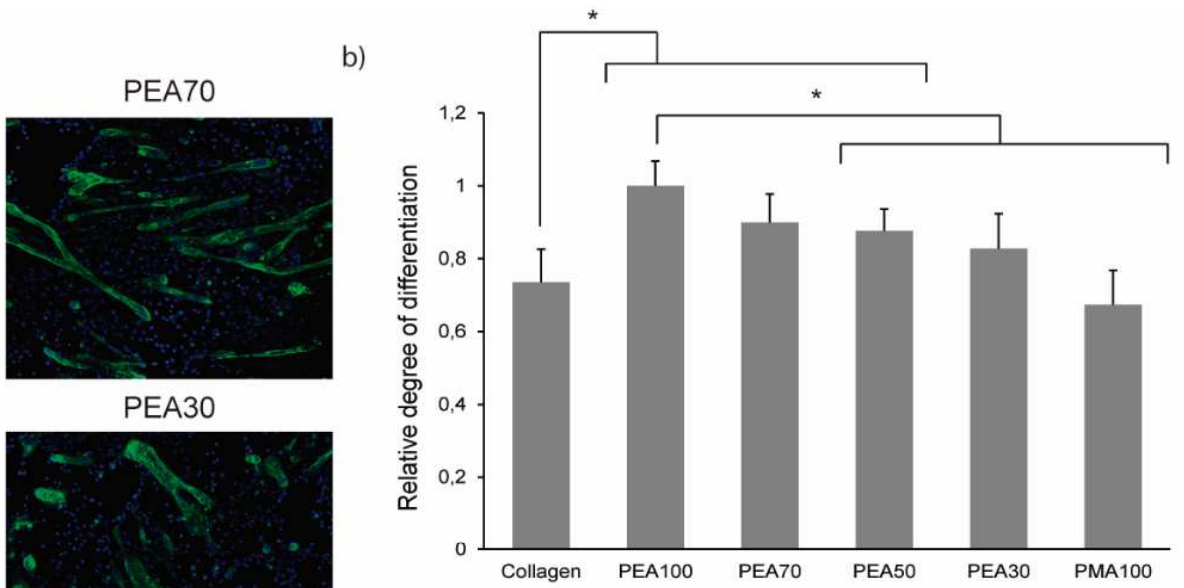

PEA30

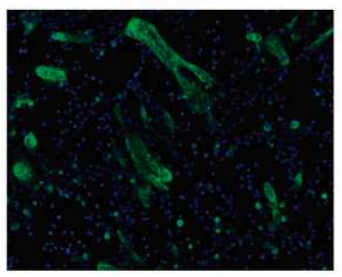

Collagen
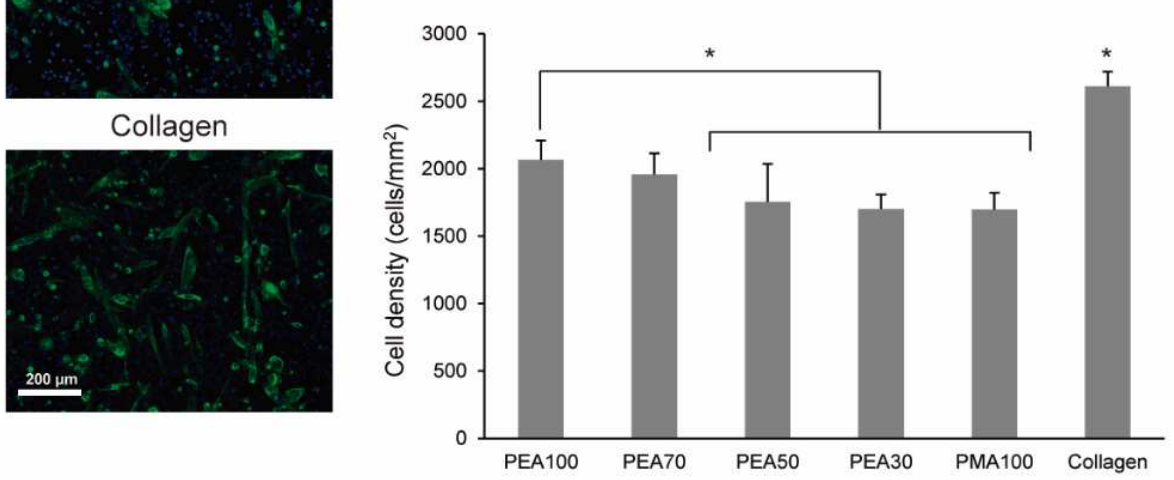

Fig. 7. Myogenic differentiation after 4 days of culture on the copolymers. a) Immunofluorescence of sarcomeric $\alpha$-actinine (green) and nuclei (blue). b) Fraction of differentiated cells normalised using the level of differentiation on PEA100. The figure at the bottom shows the cell density on the copolymers after 4 days. 
Blebbistatin is a small molecule which binds to myosin heads to form a complex with low affinity for actin and inhibit cell contractility. ${ }^{31}$ We have used blebbistatin to assess the role of contractility in the ability of different degrees of $\mathrm{FN}$ fibrillogenesis to trigger differentiation. Cell differentiation remained constant regardless of the presence of blebbistatin only for copolymers with low EA content, ie. on which FN is adsorbed with low degree of fibrillogenesis or in a globular shape (PMA) (Fig. 8). However, higher degrees of FN fibrillogenesis (on PEA100 and PEA 70) stimulated cell contractility and then differentiation, as the addition of blebbistatin reduced significantly the level of differentiation.

a)

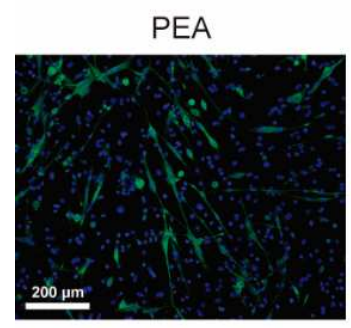

PEA 50

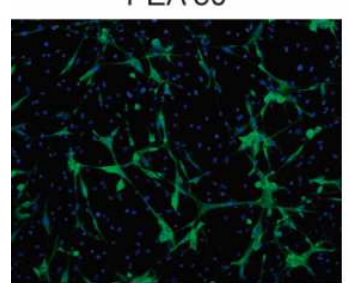

PMA

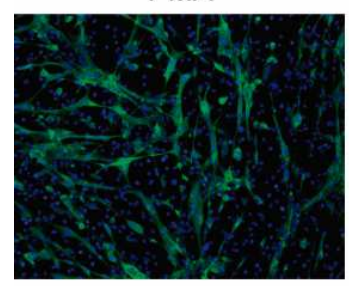

b)

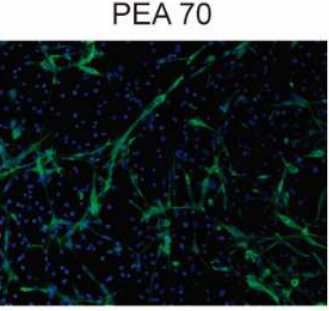

PEA 30
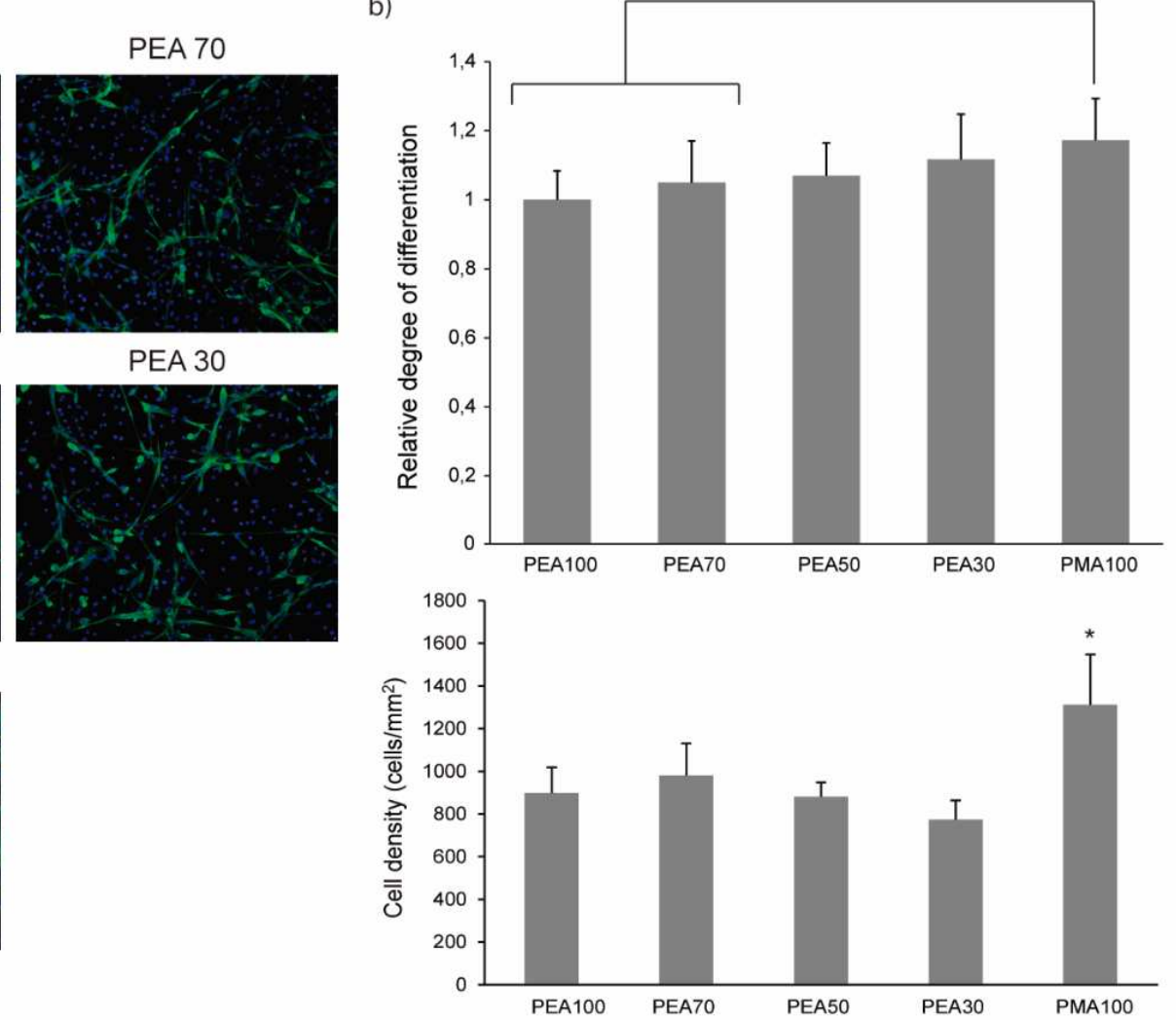

Fig. 8. Myogenic differentiation on the copolymers after 4 days of culture with blebbistatin at $10 \mu \mathrm{M}$. a) Immunofluorescence of sarcomeric $\alpha$-actinine (green) and nuclei (blue). b) Fraction of differentiated cells normalised using the level of differentiation on PEA100. The figure at the bottom shows the cell density on the copolymers after 4 days. 


\section{Discussion}

The terminal model (first-order Markov model) of copolymerization enables the estimation of copolymer composition after the polymerisation process has finished. ${ }^{32,33}$ The ratio of molar fraction of monomers $F_{1} / F_{2}$ in the copolymer can be obtained from the molar fraction of monomers $f_{1}$ and $f_{2}$ in the reaction mixture and the monomer reactivity ratios $r_{1}$ and $r_{2}$ according to the expression:

$$
\frac{F_{1}}{F_{2}}=\frac{f_{1}\left(f_{1} r_{1}+f_{2}\right)}{f_{2}\left(f_{2} r_{2}+f_{1}\right)}
$$

Reactivity ratios for EA and MA are 0.6 and 0.96 respectively. ${ }^{34}$ The higher MA reactivity ratio means that MA radicals have a higher propensity to react with MA monomers rather than with the EA ones. This behaviour can be seen in Fig. 9, where the straight line depicts the ideal random copolymers $\left(r_{1} \cdot r_{2}=1\right)$, the two monomers with equal reactivities. This ideal situation leads to a final composition of the copolymer chain that matches the comonomer solution, as well as a random distribution of co-monomers along the copolymer chain. Reactivity ratios $r_{1}$ and $r_{2}$ are not too different for MA and EA. Then, the prediction of the terminal model (equation 1) is slightly below the straight line (Fig. 9), which means that the fraction of EA units in the copolymer chain is lower than fraction of EA units in the reacting mixture. Fig. 9 shows that the fraction of EA units for the 70:30, 50:50 and 30:70 comonomer solutions turns into $66 \%, 45 \%$ and $26 \%$ respectively, i.e. the copolymer chain is less rich in EA than the original solution. This also means that the number of MA units in the copolymer chain are above the fraction of MA in the solution. The higher tendency of EA to bind MA units together with the tendency of MA to bind MA units might result in a copolymer chain that is not perfectly random distributed, but where small blocks of MA are preferentially present. 
Only one single glass transition and one main relaxation can be seen in the copolymers, which suggest no phase separation in EA and MA domains within the system. The length of cooperativity at the glass transition has been evaluated in the order of a few nanometers in amorphous polymers. ${ }^{35}$ This size determines an order of magnitude for the size domains that can show an independent glass transition in a phase-separated system. Although the terminal model suggested the potential presence of small blocks of MA in the copolymer, their size must not be large enough to produce an independent glass transition. Consistent with this approach, the copolymers present one single glass transition process located between those of the corresponding homopolymers according to its composition, following the $F_{E A} / F_{\mathrm{MA}}$ ratio.

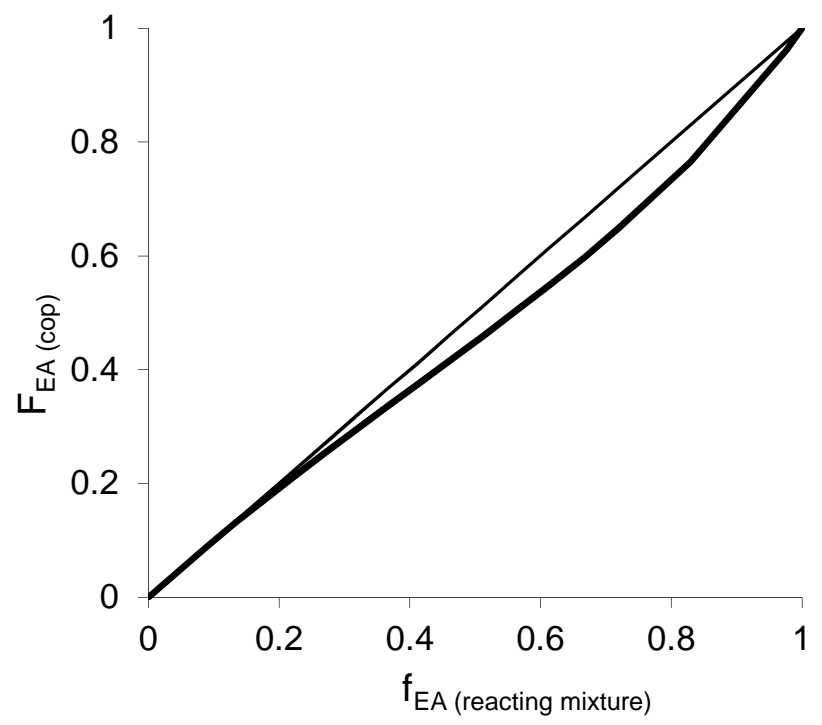

Fig. 9. Molar fraction of EA units in the copolymer as predicted by the terminal model, $F_{E A c o p}$ as a function of the molar fraction of EA monomers in the reacting mixture, $f_{E A}$, The straight line gives the composition of a random copolymer where the fraction of monomers in the reacting mixture remains after polymerization.

The composition dependence of the glass transition temperature was also compared with the prediction of the Couchman-Karasz equation for miscible polymer blends or copolymers: ${ }^{36}$

$$
T_{g}=\frac{\left(1-\omega_{P M A}\right) \Delta c_{-p P E A} T_{g-P E A}+\omega_{P M A} \Delta c_{p-P M A} T_{g-P M A}}{\left(1-\omega_{P M A}\right) \Delta c_{p-P E A}+\omega_{P M A} \Delta c_{p-P M A}}
$$


where $\omega_{P M A}$ is the mass fraction of MA in the copolymer, $\triangle c_{p-P E A}$ and $\triangle c_{p-P M A}$ are the specific heat capacity difference at $T_{g}$ for both homopolymers and $T_{g-P E A}$ and $T_{g-P M A}$ are the glass transition temperature of the PEA100 and PMA 100 homopolymers respectively. The theoretical data predicted from the model are in good agreement with the experimental results (Fig. 1b) which further confirms the homogeneity of the copolymers.

We have shown that the composition of the copolymer, i.e. the fraction of EA, determined the degree of fibrillogenesis and that this is the key parameter driving cell differentiation. Adhesion, migration and differentiation processes are dependent of both surface chemistry and stiffness ${ }^{37-39}$ in addition to the surface topography and wettability. ${ }^{40}$ Cells have an ability to sense and probe the stiffness of their surroundings as they adhere to and interact with the local ECM. ${ }^{41}$ The elastic modulus $\left(E^{\prime}\right)$ of the EA/MA copolymers vary between 0.6 and $3 \mathrm{GPa}$ (Table 1). The elastic modulus for skeletal muscle tissue is $12 \mathrm{kPa}^{42}$ Then, all copolymers can be considered as stiff surfaces from the myoblast's point of view and we can disregard the mechanical properties of the substrate stiffness, to play any role on cell behaviour. Furthermore, surface properties such as roughness (Table 1) and wettability (Fig. 2) remain constant through the copolymers, which disregard these parameters as the key to explain cellular experiments.

The material-driven FN fibrillogenesis on PEA was found to be a time- and concentrationdependent process, whose dynamics were followed via AFM at different adsorption times ${ }^{43}$, or at increasing protein concentration (for a fixed adsorption time). ${ }^{19}$.Based on these observations, the process was explained to include the following sequence of events: ${ }^{25}(i)$ Conformational change of FN upon adsorption on PEA that involves unfolding and efficient arm extension of FN upon interaction with chemical groups of the substrate (a vinyl backbone with - $\mathrm{COOCH} 2 \mathrm{CH} 3$ side chain that carries negative charge). (ii) Enhanced $\mathrm{FN}-\mathrm{FN}$ interaction as the adsorption process continues, that involves the amino-terminal $70 \mathrm{kDa}$ 
fragment, the hallmark of cell mediated FN fibrillogenesis. ${ }^{44}$ (iii) Finally, new FN molecules are preferentially adsorbed in close contact to the proteins already present in the substrate, probably as a consequence of the presence of polar oriented FN molecules. The formation of a network on PEA is not a property unique to FN. For example, a similar network was found for fibrinogen ${ }^{45}$ and collagen $\mathrm{IV}^{46}$ but only globular-isolated molecules were observed after $\operatorname{laminin}^{47}$ and vitronectin adsorption. ${ }^{48}$

Unlike PEA, FN is adsorbed in a globular shape on PMA, a polymer which differs from PEA in only one methyl group in the side chain. ${ }^{19,21}$ The organisation of FN after adsorption on the copolymers EA/MA led to different degrees of fibrillogenesis (Fig. 3a), with fibrils attaining different degrees of interconnection. Protein interconnection degree, quantified by the fractal dimension (Fig. 3b), shows the relationship between the EA/MA ratio and the degree of FN fibrillogenesis. That is to say, the EA ratio in the copolymers is a way to control the degree of FN fibrillogenesis at the material interface. It has been previously shown that the degree of fibrillogenesis can be modulated on PEA by adsorbing FN from solutions of different concentrations or by using different adsorption times. ${ }^{20,22}$ However, in both cases the total amount of FN on the surfaces changes as well, which does not happen with the copolymers shown in this work (Fig. 4a). The fact that we can control the degree of fibrillogenesis by tuning the composition of the surface further supports the concept that the organization of FN at the interface is a consequence of specific protein-material interactions. As we now have random copolymers of EA and MA, the fraction of EA groups on the surface is a reflection of the composition of the system and since only these EA groups promote the organization of fibronectin, the phenomenon occurs (at the nanoscale) but with lower length scales, i.e. lower degree of fibrillogenesis.

In addition, different degrees of FN fibrillogenesis involve also a different conformation of the protein on the surface, as revealed by the increased availability of the integrin binding 
region as the interconnection between fibrils on the material surface does. (Fig. 4b). This means that for intermediate degrees of fibrillogenesis (e.g. PEA50), the protein interface at the material interface consists of FN fibrils with the molecule in good conformation to have the integrin binding regions available and other non-fibrillar molecules on which the integrin binding site is not so well exposed. The superposition of these two kinds of fibronectin conformations results in simultaneous controlled FN organisation into fibrils, which moreover present different affinities to bind integrins. As a consequence, cells on substrates with higher degree of FN fibrillogenesis result in better cell adhesion, with slightly longer stretched cells and higher number of stress actin fibres (Fig. 5). ${ }^{49}$ In turn, cell signalling is activated more efficiently (Fig. 6b) as a consequence of the higher density of available integrin binding regions as fibrillogenesis progresses (Fig. 4b). This is well correlated with classical experiments that show a correlation between fibronectin conformation, cell adhesion and signalling using model surfaces. ${ }^{16,50}$

Myoblast differentiation occurs more effectively on substrates with higher degree of FN fibrillogenesis (Fig. 7). On the one hand, there is a direct relationship between myoblasts adhesion and differentiation, as previously shown. ${ }^{51}$ Variations of integrin expression and signalling mediated by focal adhesion kinase influence positively in myogenic differentiation. ${ }^{21,52,53}$

On the other hand, activation of cell contractility is necessary to promote differentiation. Contractile forces generated for actomyosin machinery result from dynamic interactions between actin and non-muscular myosin as a consequence of phosphorylation of myosin light chain II by several kinases as Rho associated kinases or Myosin Light Chain kinase. ${ }^{54}$ Myosins constitute a superfamily of ATP-dependent motor proteins that play important roles in several cellular processes that require force and translocation ${ }^{55}$ and within the cell regulates several function, including skeletal muscle contraction and differentiation. ${ }^{56}$ In myoblast 
differentiation and fusion process, cells produces large amounts of contractile machinery proteins such as myosin heavy chain, two myosin light chain and two subunits of tropomyosin, ${ }^{57}$ demonstrating the importance of contractile machinery in myoblast differentiation. We have previously shown that the organisation of FN into (nano)networks on PEA enhanced myoblast differentiation by activating cell contractility. ${ }^{21}$ Here, we show that when blebbistatin is added to culture medium (Fig. 8), cell differentiation drops significantly only on copolymers which show higher degree of FN fibrillogenesis, whereas it has no effect for cells on globular FN (PMA) and moderate degrees of fibrillogenesis (PEA30). This suggest a direct dependence between the degree of fibrillogenesis, the activation of cell contractility and the level of cell differentiation.

\section{Conclusions}

We have shown that material-driven FN fibrillogenesis originally described on PEA can be modulated by copolymerising EA with MA units. Increasing the amount of EA in the copolymer leads to well-organised FN (nano)networks that show better availability of the integrin binding region of FN. This fact, together with the ability of FN (nano)networks to enhance cell contractility, leads to better cell adhesion, cell signalling and myoblast differentiation by increasing the degree of FN fibrillogenesis on the material surface.

We have shown that the organisation of fibronectin into nanofibrils provides a robust platform to induce cell differentiation. ${ }^{58}$ Materials that control the degree of FN fibrillogenesis upon simple adsorption can be incorporated into novel strategies to modulate cell response in the field of tissue engineering. This series of materials can be used to coat the surface of 3D scaffolds which results in a system that is biomimetic of the extracellular matrix, with controlled density of fibrils tailored but the composition of the underlying material. This platform has the potential to become an effective approach to engineer advanced microenvironments that control the number of cell adhesion sites as well as the amount of 
growth factors used in the system to promote cell differentiation in vitro and tissue repair in vivo. We have recently submitted a patent application that presents the use of the system in tissue engineering applications, in particular musculoskeletal repair and regeneration ${ }^{59}$.

\section{Acknowledgements}

MSS acknowledges ERC through HealInSynergy 306990. The support of the project MAT2012-38359-C03-01 (including the FEDER financial support) and well as CIBER-BBN is acknowledged. CIBER de Bioingeniería, Biomateriales y Nanomedicina (CIBER-BBN, promoted by ISCIII), Spain. We also acknowledge the Electron Microscopy Service of the UPV for AFM support.

\section{References}

(1) García, A. J. Get a Grip: Integrins in Cell-Biomaterial Interactions. Biomaterials 2005, 26 (36), 7525-7529.

(2) Lan, M. A.; Gersbach, C. A.; Michael, K. E.; Keselowsky, B. G.; García, A. J. Myoblast Proliferation and Differentiation on Fibronectin-Coated Self Assembled Monolayers Presenting Different Surface Chemistries. Biomaterials 2005, 26 (22), 4523-4531.

(3) Rahmany, M. B.; Van Dyke, M. Biomimetic Approaches to Modulate Cellular Adhesion in Biomaterials: A Review. Acta Biomaterialia. 2013, pp 5431-5437.

(4) Andrade, J. D.; Hlady, V. Protein Adsorption and Materials Biocompatibility: A Tutorial Review and Suggested Hypotheses. Biopolym. HPLC 1986, 79, 1-63.

(5) Castner, D. G.; Ratner, B. D. Biomedical Surface Science: Foundations to Frontiers. Surf. Sci. 2002, 500 (1-3), 28-60.

(6) Yang, D.; Lü, X.; Hong, Y.; Xi, T.; Zhang, D. The Molecular Mechanism of Mediation of Adsorbed Serum Proteins to Endothelial Cells Adhesion and Growth on Biomaterials. Biomaterials 2013, 34 (23), 5747-5758.

(7) Allen, L. T.; Tosetto, M.; Miller, I. S.; O’Connor, D. P.; Penney, S. C.; Lynch, I.; Keenan, A. K.; Pennington, S. R.; Dawson, K. A.; Gallagher, W. M. Surface-Induced Changes in Protein Adsorption and Implications for Cellular Phenotypic Responses to Surface Interaction. Biomaterials 2006, 27 (16), 3096-3108.

(8) Lord, M. S.; Cheng, B.; McCarthy, S. J.; Jung, M.; Whitelock, J. M. The Modulation of Platelet Adhesion and Activation by Chitosan through Plasma and Extracellular Matrix Proteins. Biomaterials 2011, 32, 6655-6662.

(9) Wilson, C. J.; Clegg, R. E.; Leavesley, D. I.; Pearcy, M. J. Mediation of BiomaterialCell Interactions by Adsorbed Proteins: A Review. Tissue Eng. 2005, 11 (1-2), 1-18.

(10) Humphries, M. J.; Travis, M. A.; Clark, K.; Mould, A. P. Mechanisms of Integration of Cells and Extracellular Matrices by Integrins. Biochem. Soc. Trans. 2004, 32 (Pt 5), $822-825$.

(11) Hynes, R. O. Integrins: Bidirectional, Allosteric Signaling Machines. Cell 2002, 110, 673-687. 
(12) Schwarzbauer, J. E.; Sechler, J. L. Fibronectin Fibrillogenesis: A Paradigm for Extracellular Matrix Assembly. Curr. Opin. Cell Biol. 1999, 11 (5), 622-627.

(13) Leiss, M.; Beckmann, K.; Girós, A.; Costell, M.; Fässler, R. The Role of Integrin Binding Sites in Fibronectin Matrix Assembly in Vivo. Current Opinion in Cell Biology. 2008, pp 502-507.

(14) Mao, Y.; Schwarzbauer, J. E. Fibronectin Fibrillogenesis, a Cell-Mediated Matrix Assembly Process. Matrix Biol. 2005, 24, 389-399.

(15) Larsen, M.; Artym, V. V.; Green, J. A.; Yamada, K. M. The Matrix Reorganized: Extracellular Matrix Remodeling and Integrin Signaling. Current Opinion in Cell Biology. 2006, pp 463-471.

(16) Keselowsky, B. G.; Collard, D. M.; García, A. J. Surface Chemistry Modulates Focal Adhesion Composition and Signaling through Changes in Integrin Binding. Biomaterials 2004, 25 (28), 5947-5954.

(17) Baugh, L.; Vogel, V. Structural Changes of Fibronectin Adsorbed to Model Surfaces Probed by Fluorescence Resonance Energy Transfer. J Biomed Mater Res A. 2004, 69, 525-534.

(18) Michael, K. E.; Vernekar, V. N.; Keselowsky, B. G.; Meredith, J. C.; Latour, R. A.; García, A. J. Adsorption-Induced Conformational Changes in Fibronectin due to Interactions with Well-Defined Surface Chemistries. Langmuir 2003, 19, 8033-8040.

(19) Gugutkov, D.; González-García, C.; Rodríguez Hernández, J. C.; Altankov, G.; Salmerón-Sánchez, M. Biological Activity of the Substrate-Induced Fibronectin Network: Insight into the Third Dimension through Electrospun Fibers. Langmuir 2009, 25 (18), 10893-10900.

(20) Ballester-Beltrán, J.; Cantini, M.; Lebourg, M.; Rico, P.; Moratal, D.; García, A. J.; Salmerón-Sánchez, M. Effect of Topological Cues on Material-Driven Fibronectin Fibrillogenesis and Cell Differentiation. J. Mater. Sci. Mater. Med. 2012, 23 (1), 195204.

(21) Salmerón-Sánchez, M.; Rico, P.; Moratal, D.; Lee, T. T.; Schwarzbauer, J. E.; García, A. J. Role of Material-Driven Fibronectin Fibrillogenesis in Cell Differentiation. Biomaterials 2011, 32 (8), 2099-2105.

(22) Rico, P.; Rodríguez Hernández, J. C.; Moratal, D.; Altankov, G.; Monleón Pradas, M.; Salmerón-Sánchez, M. Substrate-Induced Assembly of Fibronectin into Networks: Influence of Surface Chemistry and Effect on Osteoblast Adhesion. Tissue Eng. Part A 2009, 15, 3271-3281.

(23) Ulmer, J.; Geiger, B.; Spatz, J. P. Force-Induced Fibronectin Fibrillogenesis in Vitro. Soft Matter 2008, 4, 1998-2007.

(24) Klotzsch, E.; Smith, M. L.; Kubow, K. E.; Muntwyler, S.; Little, C. W.; Beyeler, F.; Gourdon, D.; Nelson, B. J.; Vogel, V. Fibronectin Forms the Most Extensible Biological Fibers Displaying Switchable Force-Exposed Cryptic Binding Sites. Proc. Natl. Acad. Sci. U.S.A. 2009, 106, 18267-18272.

(25) Llopis-Hernandez, V.; Cantini, M.; Gonzalez-Garcia, C.; Salmeron-Sanchez., M. Material-Based Strategies to Engineer Fibronectin Matrices for Regenerative Medicine. Int. Mater. Rev. 2015, 60 (5), 245-264.

(26) Russel, D., Hanson, J., Ott, E. Dimension of Strange Attractors. Phys. Rev. Lett. 1980, 45 (14), 1175-1178.

(27) Abràmoff, M. D.; Magalhães, P. J.; Ram, S. J. Image Processing with imageJ. Biophotonics Int. 2004, 11 (7), 36-41.

(28) Karperien, A. FracLac for ImageJ; 2013.

(29) Eswar, N.; Webb, B.; Marti-Renom, M. A.; Madhusudhan, M. S.; Eramian, D.; Shen, M.-Y.; Pieper, U.; Sali, A. Current Protocols in Protein Science; Coligan, J. E., Dunn, 
B. M., Speicher, D. W., Wingfield, P. T., Eds.; John Wiley \& Sons, Inc.: Hoboken, NJ, USA, 2001; Vol. Chapter 2.

(30) Schultheiss, T.; Choi, J.; Lin, Z. X.; DiLullo, C.; Cohen-Gould, L.; Fischman, D.; Holtzer, H. A Sarcomeric Alpha-Actinin Truncated at the Carboxyl End Induces the Breakdown of Stress Fibers in PtK2 Cells and the Formation of Nemaline-like Bodies and Breakdown of Myofibrils in Myotubes. Proc. Natl. Acad. Sci. U. S. A. 1992, 89 (19), 9282-9286.

(31) Kovács, M.; Tóth, J.; Hetényi, C.; Málnási-Csizmadia, A.; Seller, J. R. Mechanism of Blebbistatin Inhibition of Myosin II. J. Biol. Chem. 2004, 279 (34), 35557-35563.

(32) Alfrey, T.; Goldfinger, G. The Mechanism of Copolymerization. J. Chem. Phys. 1944, $12(6), 205$.

(33) Mayo, F. R.; Lewis, F. M. Copolymerization. I. A Basis for Comparing the Behavior of Monomers in Copolymerization; the Copolymerization of Styrene and Methyl Methacrylate. J. Am. Chem. Soc. 1944, 66, 1594-1601.

(34) Brandup, J.; Immergut, E.; Grulke, E. Polymer Handbook; 1999.

(35) Fischer, E. W.; Donth, E.; Steffen, W. Temperature Dependence of Characteristic Length for Glass Transition. Phys. Rev. Lett 1992, 68, 2344.

(36) Couchman, P. R.; Karasz, F. E. A Classical Thermodynamic Discussion of the Effect of Composition on Glass-Transition Temperatures. Macromolecules 1978, 11 (1), 117 119.

(37) Tse, J. R.; Engler, A. J. Stiffness Gradients Mimicking in Vivo Tissue Variation Regulate Mesenchymal Stem Cell Fate. PLoS One 2011, 6 (1), e15978.

(38) Lo, C. M.; Wang, H. B.; Dembo, M.; Wang, Y. L. Cell Movement Is Guided by the Rigidity of the Substrate. Biophys. J. 2000, 79 (1), 144-152.

(39) Genes, N. G.; Rowley, J. A.; Mooney, D. J.; Bonassar, L. J. Effect of Substrate Mechanics on Chondrocyte Adhesion to Modified Alginate Surfaces. Arch. Biochem. Biophys. 2004, 422 (2), 161-167.

(40) Arima, Y.; Iwata, H. Effects of Surface Functional Groups on Protein Adsorption and Subsequent Cell Adhesion Using Self-Assembled Monolayers. J. Mater. Chem. 2007, 17,4079 .

(41) Discher, D. E.; Janmey, P.; Wang, Y.-L. Tissue Cells Feel and Respond to the Stiffness of Their Substrate. Science 2005, 310 (5751), 1139-1143.

(42) Gilbert, P. M.; Havenstrite, K. L.; Magnusson, K. E. G.; Sacco, A.; Leonardi, N. A.; Kraft, P.; Nguyen, N. K.; Thrun, S.; Lutolf, M. P.; Blau, H. M. Substrate Elasticity Regulates Skeletal Muscle Stem Cell Self-Renewal in Culture. Science 2010, 329, 1078-1081.

(43) Gugutkov, D.; Altankov, G.; Rodriguez Hernandez, J. C.; Monleón Pradas, M.; Salmerón Sánchez, M. Fibronectin Activity on Substrates with Controlled -OH Density. J. Biomed. Mater. Res. A, 2010, 92, 322-331.

(44) R. Pankov; Yamada, K. M. Fibronectin at a Glance. J Cell Sci 2002, 115, 3861-3863.

(45) Rodríguez Hernández, J. C.; Rico, P.; Moratal, D.; Monleón Pradas, M.; SalmerónSánchez, M. Fibrinogen Patterns and Activity on Substrates with Tailored Hydroxy Density. Macromol. Biosci. 2009, 9, 766-775.

(46) Coelho, N. M.; González-García, C.; Planell, J. A.; Salmerón-Sánchez, M.; Altankov, G. Different Assembly of Type IV Collagen on Hydrophilic and Hydrophobic Substrata Alters Endothelial Cells Interaction. Eur. Cell Mater. 2010, 19, 262-272.

(47) Rodriguez-Hernández, J. C.; Salmerón-Sánchez, M.; Soria, J. M.; Gómez Ribelles, J. L.; Monleón Pradas, M. Substrate Chemistry-Dependent Conformations of Single Laminin Molecules on Polymer Surfaces Are Revealed by the Phase Signal of Atomic Force Microscopy. Biophys. J. 2007, 93, 202-207. 
(48) Toromanov, G.; González-García, C.; Altankov, G.; Salmerón-Sánchez:, M. Vitronectin Activity on Polymer Substrates with Controlled OH Density', Polymer, 2010, 51, 2329-2336. Polymer (Guildf). 2010, 51, 2329-2336.

(49) Parsons, J. T.; Horwitz, A. R.; Schwartz, M. a. Cell Adhesion: Integrating Cytoskeletal Dynamics and Cellular Tension. Nat. Rev. Mol. Cell Biol. 2010, 11 (9), 633-643.

(50) Petrie, T. a.; Capadona, J. R.; Reyes, C. D.; García, A. J. Integrin Specificity and Enhanced Cellular Activities Associated with Surfaces Presenting a Recombinant Fibronectin Fragment Compared to RGD Supports. Biomaterials 2006, 27 (31), 54595470.

(51) Weis, S.; Lee, T. T.; Del Campo, A.; García, A. J. Dynamic Cell-Adhesive Microenvironments and Their Effect on Myogenic Differentiation. Acta Biomater. 2013, 9 (9), 8059-8066.

(52) Liu, H.; Niu, A.; Chen, S.-E.; Li, Y.-P. Beta3-Integrin Mediates Satellite Cell Differentiation in Regenerating Mouse Muscle. FASEB J. 2011, 25 (6), 1914-1921.

(53) Sastry, S. K.; Lakonishok, M.; Wu, S.; Truong, T. Q.; Huttenlocher, A.; Turner, C. E.; Horwitz, A. F. Quantitative Changes in Integrin and Focal Adhesion Signaling Regulate Myoblast Cell Cycle Withdrawal. J. Cell Biol. 1999, 144 (6), 1295-1309.

(54) Fumoto, K.; Uchimura, T.; Iwasaki, T.; Ueda, K.; Hosoya, H. Phosphorylation of Myosin II Regulatory Light Chain Is Necessary for Migration of HeLa Cells but Not for Localization of Myosin II at the Leading Edge. Biochem. J. 2003, 370 (Pt 2), 551556.

(55) Vicente-Manzanares, M.; Ma, X.; Adelstein, R. S.; Horwitz, A. R. Non-Muscle Myosin II Takes Centre Stage in Cell Adhesion and Migration. Nat. Rev. Mol. Cell Biol. 2009, 10 (11), 778-790.

(56) Griffin, M. a; Sen, S.; Sweeney, H. L.; Discher, D. E. Adhesion-Contractile Balance in Myocyte Differentiation. J. Cell Sci. 2004, 117 (Pt 24), 5855-5863.

(57) Devlin, R. B.; Emerson, C. P. Coordinate Regulation of Contractile Protein Synthesis during Myoblast Differentiation. Cell 1978, 13 (4), 599-611.

(58) Gonzalez-Garcia, C.; Moratal, D.; Oreffo, R. O. C.; Dalby, M. J.; Salmeron-Sanchez, M. Surface Mobility Regulates Skeletal Stem Cell Differentiation. Integr. Biol. 2012, 4, 531-539.

(59) Patent Application Number: GB1508931.1. Synergistic Materials for Bone Regeneration. University of Glasgow and Georgia Insitute of Technology, 2015. 
GRAPHICAL ABSTRACT
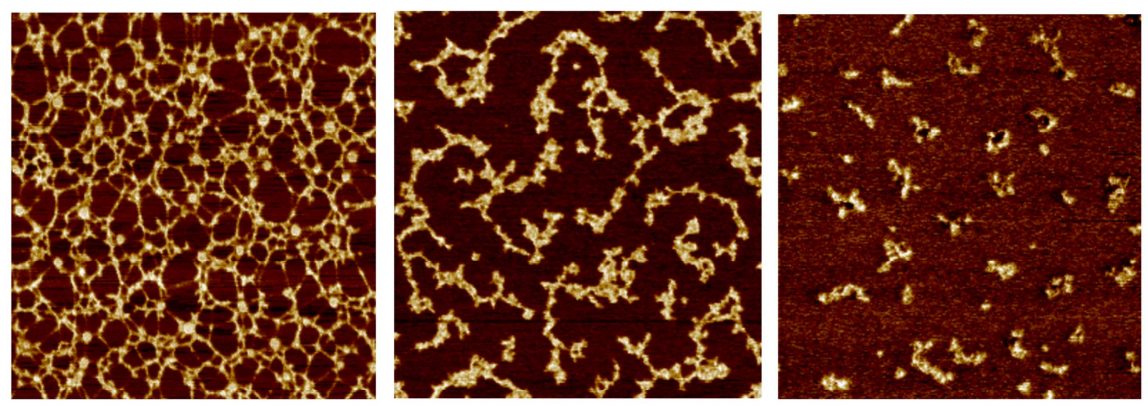